Esta revista forma parte del acervo de la Biblioteca Jurídica Virtual del Instituto de Investigaciones Jurídicas de la UNAM

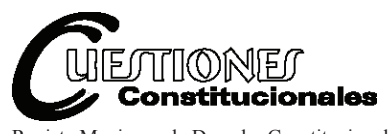

Revista Mexicana de Derecho Constitucional Núm. 36, enero-junio 2017

\title{
DERECHOS SOCIALES Y JUSTICIABILIDAD EN LA TEORÍA CONSTITUCIONAL DE INICIOS DEL SIGLO XXI
}

\author{
SOCIAL RIGHTS AND JUSTICIABILITY IN THE CONSTITUTIONAL \\ THEORY OF THE XXI CENTURY
}

\section{Diana Rocío ESPINO TAPIA*}

\begin{abstract}
RESUMEN: En este artículo proponemos una comprensión "evolucionada" de los derechos sociales a partir de los postulados del paradigma neoconstitucional. Esto se realizará a partir del análisis de los argumentos contra la justiciabilidad de los derechos sociales esgrimidos desde el positivismo jurídico, cuya resistencia será puesta a prueba frente a los argumentos teóricos del paradigma neoconstitucional. Se concluye que ante este cambio de paradigma, los argumentos positivistas han sido superados, generándose la necesidad de un cambio de perspectiva en la teoría de los derechos sociales.
\end{abstract}

Palabras clave: neoconstitucionalismo, derechos sociales, justiciabilidad.
ABSTRACT: This article aims to incorporate a proposal of an "evolved" understanding of social rights from the postulates of neoconstitutional paradigm, current in our times. This will be done through the analysis of the arguments against the justiciability of social rights put forward from the positivist paradigm, whose strength will be tested against theoretical arguments of the neoconstitutional paradigm. We conclude that facing this change of paradigm, the positivist arguments have remained obsolete, generating the necessity of a change of perspective in the theory of the social rights.

Descriptors: Neoconstitutionalism, Social Rights, Judicial Enforceability.

* Doctora en derecho con orientación en derecho constitucional y gobernabilidad por la Universidad Autónoma de Nuevo León. Investigadora en el Centro de Estudios Interculturales del Noreste (CEIN) y directora del Posgrado de Humanidades y Ciencias Sociales de la Universidad Regiomontana (Monterrey, México).diana.rocio.e@gmail. com. 
Esta revista forma parte del acervo de la Biblioteca Jurídica Virtual del Instituto de Investigaciones Jurídicas de la UNAM

SUMARIO: I. Introducción. II. El paradigma neoconstitucional y su forma de entender el derecho. III. Cinco argumentos "clásicos" contra la justiciabilidad de los derechos sociales analizados desde el neoconstitucionalismo. IV. Conclusiones. V. Bibliografía.

\section{INTRODUCCIÓN}

Nuestra pretensión aquí es presentar al lector una aproximación al debate actual sobre la justiciabilidad de los derechos sociales en el Estado constitucional contemporáneo, a partir de verificar la vigencia de los principales argumentos en contra de la justiciabilidad de estos derechos esgrimidos desde el paradigma positivista del derecho, a la luz del paradigma neoconstitucional, el cual es el que actualmente inspira al constitucionalismo latinoamericano. ${ }^{1}$ Sin embargo, no pretendemos la elaboración de un nuevo desarrollo teórico en el tema, sino proponer al lector un panorama aproximativo a este debate a partir de un análisis descriptivo-informativo. Para ello, se analizarán los cinco argumentos principales sobre los cuales consideramos que se ha construido la doctrina de los derechos sociales como derechos programáticos y no exigibles al Estado para, seguidamente, contra-argumentarlos a partir del paradigma neoconstitucional y su nueva visión del derecho.

Con fines metodológicos así como argumentativos, se otorgará primero al lector un acercamiento a los presupuestos teóricos generales del paradigma neoconstitucional para, a partir de ahí, confrontar los argumentos contrarios a la justiciabilidad de los derechos sociales defendidos por los autores positivistas cuyas posturas serán expuestas en cada uno de los apar-

1 Para esta investigación, la exigibilidad judicial y la justiciabilidad son dos conceptos distintos que constituyen dos momentos claves del proceso jurisdiccional para la tutela de los derechos sociales fundamentales. Nos referimos a la exigibilidad judicial de un derecho social cuando existen mecanismos jurisdiccionales puestos a disposición del sujeto afectado en su derecho para poder exigir su satisfacción o restitución a un tribunal jurisdiccional, mientras que la justiciabilidad del derecho social está referida a la actividad jurisdiccional llevada a cabo por los tribunales jurisdiccionales para la satisfacción del derecho social que exige reconocimiento o restitución. Esto constituye el segundo momento del proceso garantista-jurisdiccional del derecho social: una vez puesta en conocimiento del Tribunal la vulneración o desconocimiento del derecho social, éste actúa en el marco de su competencia para garantizarlo. 
Esta revista forma parte del acervo de la Biblioteca Jurídica Virtual del Instituto de Investigaciones Jurídicas de la UNAM

tados argumentativos. Con esto pretendemos demostrar que los argumentos positivistas contrarios a la exigibilidad judicial de los derechos sociales han sido superados y que debe desarrollarse una nueva teoría acorde a las aspiraciones de la nueva ciencia del derecho. La pertinencia de realizar el análisis a partir de estos argumentos consiste en que, desde el momento de la constitucionalización generalizada de los derechos sociales, éstos han constituido las barreras más sólidas en contra de la construcción de un sistema garantista de los derechos sociales a nivel interno e internacional.

\section{EL PARADIGMA NEOCONSTITUCIONAL Y SU FORMA DE ENTENDER EL DERECHO}

Con la aparición del Estado constitucional de derecho como superación del viejo Estado legalista nace el "neoconstitucionalismo" que, tal como indica su nombre, constituye una nueva forma de entender el derecho a partir de la Constitución. Éste modifica los fundamentos según los cuales se ha venido entendiendo el derecho con el fin de adaptarlos a este nuevo modelo de Estado. Atendiendo al nuevo paradigma, en el Estado constitucional ya no se analizará el derecho desde los clásicos postulados positivistas, sino que se requieren de nuevos postulados que garanticen la esencia del nuevo modelo estatal. ${ }^{2}$

Así, el neoconstitucionalismo se edifica sobre las bases del Estado constitucional, el cual se caracteriza por contar con una Constitución de fuerte contenido normativo y que cuenta con un complejo sistema de garantías - con énfasis en las garantías jurisdiccionales - para su resguardo. Se trata, en palabras de Pietro Sanchís, de “... una Constitución transformadora que pretende condicionar de modo importante las decisiones de la mayoría pero cuyo protagonismo principal no corresponde al legislador sino a los jueces". ${ }^{3}$ En referencia a su contenido normativo, Landa Arroyo destaca que esta Constitución posee eficacia normativa directa relacionada con la intención de ser "abierta y dinámica", la cual debe garantizar las dos funciones primordiales del Estado constitucional: 1) la supremacía jurídica de

2 Aragón, M., "La Constitución como paradigma", en Carbonell, M. (comp.), Teoría de la Constitución, México, Porrúa, 2008, p. 117.

3 Pietro, L., "Neoconstitucionalismo y ponderación judicial", Anuario de la Facultad de Derecho, Madrid, Universidad Autónoma de Madrid, 2001, p. 204. 
Esta revista forma parte del acervo de la Biblioteca Jurídica Virtual del Instituto de Investigaciones Jurídicas de la UNAM

la Constitución, y 2) la protección de los derechos fundamentales. ${ }^{4}$ Tomando esto en cuenta, el carácter garantista de la Constitución supone que los preceptos constitucionales pueden hacerse valer a través de los procesos jurisdiccionales diseñados para tal fin.

Desde un enfoque teórico, debemos reconocer que "neoconstitucionalismo" es un concepto que encierra en su seno diversas concepciones de este fenómeno constitucional, los cuales constituyen propuestas próximas que pueden considerarse pertenecientes a una misma aproximación teórica. ${ }^{5}$ Aquí, con el afán de ilustrar al lector sobre los presupuestos básicos del nuevo paradigma, utilizaremos la caracterización de Pietro Sanchís, quien hace un ejercicio compilador y resume sus rasgos característicos. Éstos son: a) la existencia de una Constitución normativa y principalista; b) la ponderación como forma de aplicación de las normas y principios constitucionales; c) la omnipresencia de la Constitución en todas las áreas del derecho; d) la omnipotencia judicial en lugar de la autonomía del legislador ordinario, y e) la coexistencia en la Constitución de valores plurales, en su mayoría contradictorios entre sí, en lugar de la homogeneidad ideológica. ${ }^{6}$

Este cambio de paradigma constitucional afecta de manera especial a los derechos fundamentales, pues ahora vienen a ser principios informadores del sistema, garantías en sí mismas además de normas jurídicas-constitucionales. ${ }^{7}$ De forma especial, se ha replanteado el valor constitucional de los derechos sociales y de su matriz, el Estado social de derecho. La configuración del Estado social en el constitucionalismo de mediados del siglo XX llevó a

4 Landa, C., Derechos fundamentales y justicia constitucional, México, Porrúa, 2011, p. 22.

5 Salazar, P., "Garantismo y neoconstitucionalismo frente a frente: algunas claves para su distinción”, Doxa. Cuadernos de Filosofía del Derecho, núm. 34, 2001, p. 293. Señala este autor que es precisamente por ello que cuando se habla de neoconstitucionalismo es menester reparar en las diferencias que cruzan a las obras de los autores que, no sin cierta arbitrariedad, se reúnen en esta categoría: desde Dworkin hasta Zagrebelsky, pasando por Nino y Alexy hasta Carbonell y Pulido. Leonardo García también identifica en esta línea a Joseph Aguiló, Rodolfo Arango, Laura Clericó y a los demás autores mencionados en este texto. García, L., "Buenos tiempos para el neoconstitucionalismo", Universitas, Bogotá, núm. 120, enero-junio de 2010, p. 319.

6 Pietro, L., "Neoconstitucionalismo...", cit., p. 217.

7 Adoptamos en este análisis la teoría del doble carácter de los derechos fundamentales de Hesse y Haberle en cuanto método de análisis que nos permite observar cómo los derechos sociales se manifiestan como principios informadores y normas jurídico-constitucionales. A éstos también se ha referido posteriormente Robert Alexy en su "Teoría de los derechos fundamentales" al hacer la distinción entre reglas y principios. 
Esta revista forma parte del acervo de la Biblioteca Jurídica Virtual del Instituto de Investigaciones Jurídicas de la UNAM

dotar a la Constitución de un contenido material con el afán de garantizar condiciones mínimas existenciales que hagan posible el ejercicio "real" de la libertad individual. ${ }^{8}$ Este modelo de Estado incorpora en su estructura derechos sociales - aunque no siempre de forma nominal — y sus garantías en busca de su efectivo cumplimiento. Así, en palabras de Beatriz Moreno: "El Estado asume el rol de promotor de estos derechos, donde los principios de libertad e igualdad no sean simples aspiraciones políticas sino fórmulas de cumplimiento efectivo, facilitando además la participación de los ciudadanos en los ámbitos político, económico, social y cultural". ${ }^{9}$

De esta forma, el Estado social y constitucional de derecho se identifica con los fines de su contenido social de forma que condiciona su propia actuación. En consecuencia, el neoconstitucionalismo como teoría jurídica debe construirse tomando en cuenta el carácter social del constitucionalismo contemporáneo. Es a partir de este nuevo paradigma jurídico desde donde vamos a contra-argumentar las posiciones positivistas en torno al debate sobre la justiciabilidad de los derechos sociales.

\section{CinCO ARGUMENTOS "CLÁSICOS” CONTRA}

LA JUSTICIABILIDAD DE LOS DERECHOS SOCIALES

ANALIZADOS DESDE EL NEOCONSTITUCIONALISMO

\section{La imposibilidad del carácter subjetivo de los derechos sociales}

Afirma Cruz Parcero que muchas de las críticas y posiciones escépticas sobre los derechos sociales se apoyan en una concepción positivista desde la cual se concibe el concepto de derecho subjetivo. Sostiene que ésta, a su vez, parte de la concepción kelseniana que entiende los derechos subjeti-

8 Es lo conocido como el concepto de "Daseinvorsorge" formulado por Forsthoff en 1938 y recogido por la doctrina germana para caracterizar el Estado social. En este concepto se subraya las medidas concretas necesarias para satisfacer las necesidades vitales de los individuos en las actuales sociedades modernas. García Pelayo considera el concepto de "procura existencial" como: "La acción estatal destinada a crear las condiciones para la satisfacción de aquellas necesidades vitales, en las complejas condiciones de la sociedad de nuestro tiempo, no pueden ser satisfechas por el individuo ni por el grupo". García Pelayo, M., Obras completas, Madrid, Centro de Estudios Constitucionales, 1991, t. II, p. 36.

9 Moreno, B., El Estado social: naturaleza jurídica y estructura de los derechos sociales, Madrid, Civitas, 2004, p. 45. 
Esta revista forma parte del acervo de la Biblioteca Jurídica Virtual del Instituto de Investigaciones Jurídicas de la UNAM

vos, en sentido estricto, como poderes que tiene el sujeto para exigirle al Estado el cumplimiento de un deber jurídico a otro sujeto. Para Cruz, esta noción se ubica en la idea de "acción procesal", por la cual no basta que un derecho esté reconocido en una ley; si no existe un remedio judicial para hacerlo valer ante un juez, no es en estricto un derecho. Además, señala que la visión positivista del derecho subjetivo está estrechamente vinculada al origen liberal del concepto, pues sostiene que el derecho subjetivo surge en la modernidad, en la forma de derechos privados, referidos a los derechos de propiedad, de crédito y contractual. ${ }^{10}$

Esta postura "clásica" que niega el carácter subjetivo a los derechos sociales es aún férreamente defendida por cierto sector del constitucionalismo contemporáneo. Existe un caso en particular el cual ejemplifica esta postura, por colocar sobre la mesa sus argumentos más importantes. En un conocido artículo, Fernando Atria ha señalado que los derechos sociales son una contradicción con la esencia misma del concepto de derecho subjetivo. Así, por la naturaleza de este concepto y por su carácter exigible, los derechos sociales no pueden ser concebidos como derechos subjetivos, pues no configuran los elementos para merecer la forma de protección judicialmente exigible que es propia de los derechos civiles y políticos. En este autor encontramos el punto de intersección entre la negación de los derechos sociales como derechos subjetivos y la consideración de estos derechos como derechos de ejercicio colectivo. Desde su planteamiento, si los derechos sociales son derechos que persiguen fines de una colectividad, entonces son de ejercicio colectivo. Por lo tanto, no pueden ser derechos subjetivos, precisamente porque en la naturaleza de estos últimos está la individualidad del sujeto. ${ }^{11}$

Refutaremos en primer lugar el argumento de la titularidad colectiva de los derechos sociales, para luego centrarnos en el argumento que les niega el carácter de derechos subjetivos. Respecto a la primera de estas cuestiones, consideramos que hay una confusión en lo referente a la titularidad del derecho y a su ejercicio. Si nos referimos — por ejemplo - al derecho de huelga, es evidente que para su efectivo ejercicio se requiere de un colectivo de trabajadores inconformes con la empresa para que su reclamo sea

10 Cruz Parcero, J., El lenguaje de los derechos. Ensayo para una teoría estructural de los derechos, Madrid, Trotta, 2007, pp. 71-76.

11 Atria, F., “Existen derechos sociales?”, Discusiones, La Pampa, Universidad Nacional del Sur, año 4, núm.4, febrero de 2005, pp. 15-59. 
Esta revista forma parte del acervo de la Biblioteca Jurídica Virtual del Instituto de Investigaciones Jurídicas de la UNAM

escuchado. Pero esto no significa que la titularidad del derecho de huelga sea del colectivo, sino que el derecho se "individualiza" en cada uno de los trabajadores que participan en la huelga. En este sentido, bien afirma Contreras Peláez que "sólo en sentido metafórico puede hablarse de las necesidades de un pueblo, de un país o de una clase: 'El hambre en Somalia' se resuelve en siete millones de (espantosas) hambres individuales". ${ }^{12}$ Por otra parte, no sólo los derechos sociales requieren para su efectividad de mecanismos de ejercicio colectivo. Por ejemplo, podemos observar que si un grupo de manifestantes se reúne para protestar en contra de una ley que limita el acceso a la información sobre las actividades de la administración pública, están ejerciendo su derecho a la libertad de expresión con mecanismos colectivos, sólo así podría ser plenamente efectivo el ejercicio de su derecho individual.

Pero la problemática se concentra definitivamente en la consideración de los derechos sociales como derechos subjetivos. A partir del positivismo jurídico, Torres del Moral retoma el concepto de "derecho subjetivo" elaborado en los años setenta por García de Enterría, quien señala que consiste en "la posibilidad atribuida al individuo de poner en movimiento una norma jurídica en su propio interés". ${ }^{13}$ A partir de ahí, Torres resalta al "interés" como el elemento sustancial del derecho. Luego, su elemento formal lo constituye la protección que le dispensa el ordenamiento jurídico. Afirma que si, además, se añade que estos derechos son públicos, entonces: "se pone en relieve que son exigibles frente al Estado, frente a los poderes públicos". ${ }^{14}$ Como correspondía al modelo del Estado liberal, este interés jurídicamente protegido consistía en la abstención de toda actuación estatal que interfiriera en la esfera de libertad del individuo; limitación precisada en la norma jurídica. Consecuentemente, los autores que niegan a los derechos sociales la categoría de derechos subjetivos estiman que esta categoría es insuficiente en el Estado social, por la razón que los derechos sociales exigen una actuación estatal activa, de promoción y de prestación, obligación generalmente imprecisa para poder generar un derecho subjetivo exigible. ${ }^{15}$

12 Contreras, J., Derechos sociales: teoría e ideología, Madrid, Tecnos, 1994, p. 31.

13 García de Enterría, E., "Sobre los derechos públicos subjetivos", Revista Española de Derecho Administrativo, Madrid, núm. 6, 1975, pp. 427-446.

14 Torres del Moral, A., "Naturaleza de los derechos constitucionales", Revista de Derecho de la Universidad Católica de Valparaíso, Valparaíso, Universidad Católica, vol. XVIII, 1997, pp. 150.

15 Para efectos ilustrativos en este enunciado, recurriremos al concepto de derecho 
Esta revista forma parte del acervo de la Biblioteca Jurídica Virtual del Instituto de Investigaciones Jurídicas de la UNAM

Sin embargo, desde la perspectiva neoconstitucional, los derechos sociales sí pueden ser considerados derechos subjetivos, pero el concepto de derecho subjetivo tendría que ser entendido de manera distinta, es decir, desde una perspectiva "evolucionada" del concepto. Esta idea es propuesta por Rodolfo Arango, quien - partiendo de la teoría de los derechos fundamentales de Robert Alexy - defiende la tesis que afirma que los derechos sociales como derechos subjetivos deber ser entendidos en sentido estricto como "posiciones o relaciones normativas para las cuales es posible dar razones válidas y suficientes y cuyo no reconocimiento injustificado ocasiona un daño inminente a la persona". ${ }^{16}$ Estas posiciones normativas implican la exigencia de prestaciones positivas fácticas por parte del Estado, que tienen como objeto un hacer positivo de la parte obligada. ${ }^{17}$

Este concepto evolucionado de derecho subjetivo de Arango - que implica a los derechos sociales fundamentales - parte de tres supuestos: 1) en una Constitución democrática, la titularidad de los derechos sociales fundamentales no proviene directamente del texto constitucional sino de las normas adscritas de derecho fundamentales a partir de una correcta argumentación jurídica; 2) la existencia de deberes constitucionales provenientes de la inferencia de derechos positivos a partir de derechos constitucionales implícitos no implica sin más el carácter subjetivo de los derechos sociales, y 3 ) el derecho subjetivo se obtiene en cada caso concreto, a partir de la justificación del estado de necesidad y la fundamentación de una posición jurídico-constitucional que otorgue el reconocimiento y aseguramiento del derecho social fundamental en específico, con fundamento en el respeto al

subjetivo propuesto por Guastini, que resulta conveniente por su claridad y precisión. Según Guastini, el derecho subjetivo es: "una pretensión conferida a un sujeto (o a una clase de sujetos) frente a otro sujeto (o a otra clase de sujetos) a los que se impone un deber (una obligación) correlativo". En efecto, los derechos pueden dividirse en derechos verdaderos y "derechos sobre el papel". Los derechos verdaderos se caracterizan porque son susceptibles de tutela jurisdiccional, lo que requiere que el contenido del derecho (el comportamiento o prestación que puede exigirse) y el sujeto frente al que se ejerce el derecho se defina con precisión. Por otro lado, los derechos "sobre el papel" son los que no cumplen con estas condiciones, de forma que no son susceptibles de tutela jurisdiccional. Desde esta concepción del derecho subjetivo, señala Guastini que los derechos sociales pertenecen al segundo grupo, son derechos "sobre el papel". Guastini, R., "Derechos", Distinguiendo, Barcelona, Gedisa, núm. 199, p. 180.

16 Arango, R., El concepto de derechos sociales fundamentales, Bogotá, Legis, 2012, pp. 304 y ss.

17 Idem. 
Esta revista forma parte del acervo de la Biblioteca Jurídica Virtual del Instituto de Investigaciones Jurídicas de la UNAM

principio de dignidad humana al interior del Estado social y democrático de derecho. ${ }^{18}$

En efecto, para Arango los derechos sociales fundamentales son "derechos subjetivos con un alto grado de importancia". ${ }^{19}$ Su adscripción como derecho general positivo radica en el derecho de una persona a acciones fácticas que han de ser garantizadas por el Estado, constituyéndose así como derechos fundamentales en sentido pleno. ${ }^{20}$ Para este autor, la exigibilidad judicial de los derechos sociales

puede ser justificada a partir de un concepto evolucionado de los derechos subjetivos [el cual] exige comprender el funcionamiento de la interpretación constitucional y del ejercicio de los derechos en la práctica, de manera que sea posible reconstruir las condiciones formales y materiales necesarias para el reconocimiento judicial de los derechos sociales fundamentales. ${ }^{21}$

En definitiva, la propuesta de Arango actualiza el concepto de derecho subjetivo al adaptarlo a los nuevos tiempos y a las exigencias del nuevo constitucionalismo social. En este contexto, los derechos sociales como derechos subjetivos deben definirse en cada caso concreto, a partir de la interpretación constitucional que los jueces desarrollen para la aplicación del derecho al hecho y dependiendo de ciertos factores que evidencien una posición jurídico-constitucional del individuo y la exigencia de tutela jurisdiccional. La propuesta de Arango es producto de su ejercicio jurisdiccional en la Corte Constitucional Colombiana, donde previamente han reconocido derechos sociales fundamentales a partir de su interpretación como derechos subjetivos. ${ }^{22}$

También el Tribunal Constitucional peruano ha desarrollado en la práctica jurisdiccional el ejercicio de "subjetivación" de un derecho social para su exigibilidad, como el propuesto aquí por Arango. Este Tribunal ha señalado que aunque la naturaleza claramente prestacional del derecho social hace imposible su exigibilidad judicial en todos los casos, existen casos en los

18 Ibidem, pp. 10-30.

19 Ibidem, p. 32.

20 Ibidem, p. 321.

21 Arango, R., "La justiciabilidad de los derechos sociales fundamentales", Revista de Derecho Público, Bogotá, Universidad de los Andes, Facultad de Derecho, núm. 12, junio de 2001, pp. 186.

22 Corte Constitucional Colombiana, Sentencia T-406 de 1992. 
Esta revista forma parte del acervo de la Biblioteca Jurídica Virtual del Instituto de Investigaciones Jurídicas de la UNAM

que el derecho se individualiza y es posible determinar su aspecto judicialmente exigible. Estos son los casos en que el derecho social se manifiesta como derecho subjetivo y se evidencia el daño que el desconocimiento del derecho social provoca en la persona. Así lo expresa en su sentencia STC 2945-2003-AA:

...los derechos sociales, como la salud pública, no pueden ser exigidos de la misma en todos los casos, pues no se trata de prestaciones específicas, en tanto dependen de la ejecución presupuestal para el cumplimiento de los exigido, lo contrario supondría que cada individuo podría exigir judicialmente al Estado un puesto de trabajo o una prestación específica de vivienda o salud en cualquier momento. En consecuencia, la exigencia judicial de un derecho social dependerá de factores tales como la gravedad y razonabilidad del caso, su vinculación o afectación de otros derechos y la disponibilidad presupuestal del Estado, siempre y cuando puedan comprobarse acciones concretas de su parte para la ejecución de políticas sociales. ${ }^{23}$

\section{La negativa a considerar a los derechos sociales como derechos po- sitivos}

Este argumento está estrechamente vinculado al anterior. Aunque en muchos estudios sobre el tema se ha analizado el derecho subjetivo a partir de su consideración como derecho positivo, en este estudio ambos conceptos se toman como unidades de análisis distintas, pero relacionadas.

De acuerdo con Aguiló, en el paradigma positivista, los enunciados jurídicos de derechos relativos a una persona o un grupo de personas son siempre reducibles a enunciados de deberes de otro u otros sujetos. Es decir, derechos y deberes son correlativos. ${ }^{24}$ Desde esta perspectiva, los derechos sociales han sido considerados normas jurídicas indeterminadas y, por lo tanto, sin deberes definidos. La consecuencia obligada de este razonamiento sería que sin deber correlativo, no existe derecho. Desde esta postura, Hayek ha observado la indeterminación del sujeto pasivo de esta relación jurídico-obligacional, razón por la cual sostiene que no constituyen más

23 Tribunal Constitucional Peruano, StC 2945-2003-AA/TC, Sentencia del 20 de abril de 2004, Fj. 22.

24 Aguiló, J., "Positivismo y post-positivismo. Dos paradigmas jurídicos en pocas palabras", Doxa. Cuadernos de Filosofía del Derecho, Alicante, Universidad de Alicante, núm. 30, 2007, pp. 665-675. 
Esta revista forma parte del acervo de la Biblioteca Jurídica Virtual del Instituto de Investigaciones Jurídicas de la UNAM

que simples aspiraciones o fines programáticos del Estado, por lo tanto no resultan exigibles. ${ }^{25}$ También Bockenforde ha negado que los derechos sociales generen deberes concretos por su necesidad de concreción mediante políticas legislativas; razón por lo cual sólo cumplen una función política como "mandatos jurídicos objetivos" además de facultar al legislador para limitar los derechos de libertad. ${ }^{26}$

La negación del carácter de derecho positivo a los derechos sociales ha estado relacionada desde siempre con la estructura del derecho social, específicamente con la naturaleza de la obligación jurídica. Sostiene Pisarello que la doctrina clásica resalta que el elemento diferenciador de los derechos liberales con respecto a los sociales es la naturaleza de las obligaciones, que en el caso de los primeros se trataría de obligaciones negativas o de abstención y en el caso de los segundos se trataría de obligaciones positivas o de acción. En consecuencia, sólo serían jurídicamente exigibles los derechos individuales, que son los que exigen abstenciones por parte del Estado. ${ }^{27}$

Esta visión cambia drásticamente si observamos el problema desde el paradigma neoconstitucional. Señala Aguiló que en términos meramente regulativos es cierto que los enunciados son traducibles a enunciados de deberes; sin embargo, en términos justificativos, la correlación entre derechos y deberes se pierde y, por lo tanto, la traducción de los enunciados de derechos a enunciados de deberes invirtiendo los sujetos sí supone una

$25 \mathrm{Al}$ respecto, este autor ha llegado a señalar que los derechos sociales son en el presente y para todo futuro previsible, absolutamente imposibles de alcanzar además de "ilusiones" y aspiraciones que envilecen el término "derecho". Hayek, F., Derecho legislación y libertad. El espejismo de la justicia social, Madrid, Unión Editorial, vol. 2, 1979, p. 308 .

26 Bockenforde, E., "Los derechos fundamentales sociales en la estructura de la Constitución", Escritos sobre derechos fundamentales, Baden-Baden, Nomos, 1993, pp. 78 y ss. Esto es a lo que Ruiz Miguel denomina la "visión conservadora" de los derechos sociales. Esta posición señala que debido a las diferencias estructurales y a la importancia de los derechos liberales respecto a los sociales, solamente los primeros son básicos, universales, incondicionales e indeclinables mientras que los segundos configuran meras aspiraciones ideales, condicionadas, particulares y subordinables, de tal forma que sólo constituyen derechos fundamentales los primeros, mientras que llamar "derechos sociales" a los segundos resulta engañoso. Ruiz Miguel, A., "Derechos liberales y derechos sociales", Doxa. Cuadernos de Filosofía del Derecho, Madrid, núms. 15 y 16, 1994, p. 653.

27 Pisarello, G., Los derechos sociales y sus garantías. Elementos para una reconstrucción, Madrid, Trotta, 2007, pp. 59 y ss. 
Esta revista forma parte del acervo de la Biblioteca Jurídica Virtual del Instituto de Investigaciones Jurídicas de la UNAM

pérdida de significación. ${ }^{28}$ Afirma en este sentido: "El reconocimiento de derechos justifica la imposición de deberes, mientras que la imposición de deberes no sirve para justificar la titularidad de los derechos". ${ }^{29}$ En efecto, los derechos sociales constituyen derechos positivos pues toda persona es efectivamente titular de estos derechos reconocidos constitucionalmente, con independencia de que el Estado haya creado o no mecanismos para su exigibilidad ni haya concretado al sujeto obligado de la relación..$^{30}$ En palabras de Pietro Sanchís, que los derechos sociales sean indeterminados "no representa ninguna dificultad a su carácter vinculante." 31

Además, la clásica distinción entre derechos basada en la naturaleza de sus obligaciones ha perdido vigencia. La discusión doctrinal actual está centrada en el análisis del continuum de obligaciones que supone cada derecho en sus manifestaciones, en la que cada derecho fundamental, sea liberal o social, está compuesto tanto por obligaciones negativas o de abstención como por obligaciones positivas o de hacer. ${ }^{32}$ En este sentido, la estructura de los derechos fundamentales, en general, consiste en un "espectro de obligaciones"; es decir, las manifestaciones de estos derechos pueden contener obligaciones que son, en un extremo, obligaciones negativas, que consisten en abstenerse de actuar en ciertos ámbitos y, en el otro extremo, obligaciones positivas, que consisten en realizar ciertas funciones a efecto de garantizar el desarrollo de la personalidad del ser humano. ${ }^{33}$

Por lo mismo, Abramovich y Courtis sostienen que las diferencias entre los derechos individuales y los derechos sociales son diferencias de grado más que diferencias sustanciales. ${ }^{34}$ Para los autores, resulta evidente que la faceta más visible de los derechos sociales es la de contener obligaciones positivas; sin embargo, existen ciertas manifestaciones de estos derechos que

28 Aguiló, J., "Positivismo y post-positivismo..., cit., p. 670.

29 Ibidem, p. 671.

30 Cruz Parcero, J., "Derechos sociales: clasificaciones sospechosas y delimitación conceptual", en Cantón, Octavio y Corcuera, Santiago (coords.), Derechos económicos, sociales y culturales. Ensayos y materiales, México, Porrúa, 2004, pp. 3-14.

31 Prieto Sanchís, L., Ley, principios, derechos, Madrid, Dykinson, 1998, p. 98.

32 Pisarello, G., Los derechos..., cit., pp. 76 y 77.

33 Sepúlveda, M., "La justiciabilidad de los derechos económicos, sociales y culturales frente a la supuesta dicotomía entre las obligaciones impuestas por los pactos de Naciones Unidas", en Cantón, Octavio y Corcuera, Santiago (coords.), Derechos económicos, sociales y culturales. Ensayos y materiales, cit.

34 Abramovich, V. y Courtis, C., Derechos sociales como derechos exigibles, Madrid, Trotta, 2002, pp. 24 y 25. 
Esta revista forma parte del acervo de la Biblioteca Jurídica Virtual del Instituto de Investigaciones Jurídicas de la UNAM

contienen en su seno obligaciones de abstención. Como ejemplo proponen el derecho a la salud el cual, en su manifestación de derecho-libertad, exige la obligación por parte del Estado de no dañar la salud de sus ciudadanos (por ejemplo, realizando campañas de esterilización sin consentimiento informado de las afectadas). De esta forma, señalan Abramovich y Courtis: "Muchas de las acciones legales tendentes a la aplicación judicial de los derechos sociales se dirigen a corregir la actividad estatal cuando ésta incumple con obligaciones de no hacer". ${ }^{35}$

Por ello, aquí asumimos que los derechos sociales están compuestos por un espectro de obligaciones positivas y negativas por parte del Estado, aunque las obligaciones positivas sean su faceta más visible y característica. Por lo tanto, consideramos anacrónica la clásica distinción entre derechos de abstención - derechos de prestación y aceptamos la postura que defiende la multidimensionalidad de todos los derechos fundamentales. Esta idea no se ha quedado sólo en el ámbito académico-doctrinal, sino que también ha sido defendida en la jurisprudencia constitucional comparada, como el caso de la sentencia T-595 del 2002 de la Corte Constitucional Colombiana, donde se ha afirmado:

En la sociedades modernas, donde el uso de la libertad individual depende de acciones y prestaciones públicas — servicio público de transporte, de telecomunicaciones, de salud, etcétera-y donde la seguridad personal cuesta, no es posible sostener la tesis del carácter negativo de las libertades básicas. Por el contrario, la infraestructura necesaria para hacer posible el ejercicio de las libertades fundamentales, los derechos de defensa y debido proceso o los derechos políticos, requiere de grandes erogaciones económicas y de la actuación permanente y coordinada por parte del Estado. La fuerza pública, la administración de justicia y la organización electoral, aunque parezcan obvias en un Estado de derecho, constituyen la dimensión prestacional de las libertades básicas. ${ }^{36}$

Y más recientemente, también la Suprema Corte de Justicia de México se ha pronunciado asumiendo las multidimensionalidad de los derechos sociales. En el amparo en revisión 378/2014 referido al derecho a la salud, se denuncia a las autoridades mexicanas por omitir su obligación de asignar presupuesto para la ejecución de un proyecto en beneficio de los enfermos

35 Idem.

36 Corte Constitucional Colombiana, T-595 de 2002, párrafo 5.1. 
Esta revista forma parte del acervo de la Biblioteca Jurídica Virtual del Instituto de Investigaciones Jurídicas de la UNAM

de VIH y otras enfermedades de transmisión aérea. En aquella sentencia, señaló la Corte:

En esa lógica, se trata de un derecho complejo que despliega una amplia serie de posiciones jurídicas fundamentales para los particulares y para el Estado, en el entendido que la protección de la salud y el desarrollo de los correspondientes sistemas sanitarios asistenciales es una de las tareas fundamentales de los Estados democráticos contemporáneos y representa una de las claves del Estado de bienestar... Así, la salud es una meta prioritaria en sí misma y, a su vez, es el pilar estratégico para que existan otras prerrogativas, ya que las posibilidades de que sean capaces los individuos para desplegarlas como tales, dependen de los logros en salud, en tanto un Estado de bienestar general resulta indispensable para poder ejercer el resto de los derechos humanos que tutela la Constitución federal y, en consecuencia, para poder llevar una vida digna. ${ }^{37}$

\section{Los derechos sociales requieren de un fuerte presupuesto estatal para su ejecución}

Este argumento defiende la idea de que los derechos sociales, a diferencia de los individuales, requieren para su realización de una fuerte inversión económica y que no se puede exigir al Estado la satisfacción de estos derechos si no dispone de los recursos para ello. ${ }^{38}$ Esta es la razón por la cual son consideradas normas programáticas, pues su satisfacción requiere, en gran medida, de una situación económica favorable. Como la situación económica de un Estado no es algo que pueda preverse con facilidad, entonces los derechos sociales, en situación de crisis, pueden no ser satisfechos. Esto a diferencia de los derechos individuales, que poseen garantías jurisdiccionales que se ponen en marcha en caso de vulneración. Al respecto, señala Pisarello que los derechos sociales — desde su origen - fueron considerados derechos prestacionales y caros, constituyendo un factor determinante a la

37 Suprema Corte de Justicia de México, Amparo en revisión 378/2014, pp. 27 y 28.

38 Señala Melo de Moraes que esto constituye, según lo señalado por el Tribunal Constitucional Alemán, "la reserva del posible" y destaca como uno de los argumentos más esgrimidos contra la eficacia jurídica de los derechos sociales la denominada "disponibilidad económica". Melo de Moraes, N., La contribución del Poder Judicial a la protección de los derechos humanos de tercera generación: Especial referencia al derecho al desarrollo, Salamanca, Universidad de Salamanca, 2014, p. 293. 
Esta revista forma parte del acervo de la Biblioteca Jurídica Virtual del Instituto de Investigaciones Jurídicas de la UNAM

hora de justificar su protección debilitada. ${ }^{39}$ También Bustos observa que es indiscutible que para el positivismo jurídico, los derechos sociales pueden ser relativizados y tendrían una eficacia jurídica debilitada por depender de la economía estatal en cada momento histórico, mientras que los derechos individuales siempre tendrán que ser respetados. ${ }^{40}$

Desde la perspectiva neoconstitucional, el argumento de la disponibilidad económica no resulta aceptable. Si tenemos en cuenta lo señalado en el apartado anterior, en este paradigma todos los derechos fundamentales - tanto los individuales como los sociales - poseen obligaciones multidimensionales, las cuales exigen de diversos grados de inversión estatal. En un importante estudio bastante conocido, Holmes y Sustein demostraron empíricamente - desde la realidad jurídica-económica estadounidenseque todos los derechos fundamentales requieren de la erogación de importantes cantidades para su realización y que este argumento responde más a prejuicios ideológicos que a la realidad ${ }^{41}$ Si retomamos la idea de que entre derechos liberales y derechos sociales existen sólo diferencias de grado, podremos deducir que, en general, todos los derechos fundamentales generan costos al Estado, aunque en mayor o menor medida. En efecto, todos los derechos civiles y políticos entrañan, al igual que los derechos sociales, una dimensión distributiva. En palabras de Pisarello: "Lo que está en juego, por lo tanto, no es cómo garantizar los derechos más caros, sino decidir cómo y con qué prioridades se asignan los recursos que la satisfacción de todos los derechos exige". ${ }^{42}$

Por otra parte, el hecho de considerar los derechos sociales como derechos prestacionales que requieren de recursos del Estado y, por lo tanto, dependen de su disponibilidad económica, no significa que el legislador tenga total discrecionalidad en asignar los recursos para las políticas públicas destinadas a satisfacer derechos sociales, ni que se justifique su inacción para legislar en la materia. Al respecto, Courtis menciona que tanto la jurisprudencia nacional como internacional han recalcado que el reconocimiento de los derechos sociales a nivel constitucional genera la

39 Pisarello, G., Los derechos..., cit., pp.76 y 77.

40 Bustos, R., "Derechos sociales: Desmontando prejuicios", en Figueroa, A., Los derechos humanos en los umbrales del siglo XXI, México, UNAM, Instituto de Investigaciones Jurídicas, 2012, pp. 135-159.

41 Holmes, S. y Sustein, C., The Cost of Rights: Why Liberty Depends on Taxes, Nueva York, Norton, 2000.

42 Pisarello, G., Los derechos..., cit., p. 61. 
Esta revista forma parte del acervo de la Biblioteca Jurídica Virtual del Instituto de Investigaciones Jurídicas de la UNAM

obligación inmediata de desarrollarlos progresivamente con la consecuente prohibición de regresión, por lo cual su no-desarrollo tendría que estar justificado por la situación económica del Estado, siempre y cuando sea evidente que el Estado ha tomado algunas acciones tendentes a desarrollar los derechos sociales. ${ }^{43}$ Esta exigencia cobra mayor importancia en el actual escenario político latinoamericano donde la historia reciente evidencia cómo se ha extendido la corrupción en el continente, la cual, como señala Perfecto Ibáñez, "por su extensión e importancia, distan de representar una anécdota de ilegalidad para constituir un nuevo fenómeno macroscópico de degradación criminal del poder". ${ }^{44}$

Con respecto a la prohibición de regresividad, el Comité de Derechos Económicos, Sociales y Culturales de las Naciones Unidas - en su Observación E/C.12/2007/1 del 21 de setiembre del 2007- ha determinado cómo comprender el compromiso estatal de "adoptar medidas hasta el máximo de los recursos de que disponga", cuando el Estado alegue no contar con recursos suficientes para cumplir con estas obligaciones. ${ }^{45} \mathrm{Al}$ respecto, señaló que la garantía de los derechos sociales "no exige forzosamente importantes asignaciones de recursos" ${ }^{46}$ A continuación, estableció que en caso que un Estado alegue limitaciones de recursos para justificar la adopción de medidas regresivas, se consideraría una serie de criterios objetivos para examinar la validez de la regresión, los que son: 1) el nivel de desarrollo del país, 2) la gravedad de la infracción en el disfrute de los derechos básicos del pacto, 3) la situación económica del país en ese momento, teniendo particularmente en cuenta si atraviesa un periodo de recesión económica, 4) la existencia de otras necesidades acuciantes que el Estado deba atender de manera prioritaria, 5) si el Estado intentó encontrar opciones de bajo costo,

43 Courtis, C., El mundo prometido. Escritos sobre derechos sociales y derechos humanos, México, Fontamara, 2009.

44 Ibáñez, P., "Democracia con jueces", en Malem, Jorge et al. (comp.), La función judicial. Ética y democracia, Barcelona, Gedisa, 2003, p. 248.

45 Comité de los Derechos Económicos, Sociales y Culturales de la ONU, Evaluación de la obligación de adoptar medidas hasta el "máximo de los recursos de que disponga" de conformidad con un Protocolo Facultativo del Pacto, E/C.12/2007/1, 21 de setiembre de 2007, disponible en: http://www2.ohchr.org/english/bodies/cescr/docs/ E.C.12.2007.1_sp.pdf(consultada el 31 de julio de 2015).

46 Ibidem, punto 7. 
Esta revista forma parte del acervo de la Biblioteca Jurídica Virtual del Instituto de Investigaciones Jurídicas de la UNAM

y 6) si el Estado parte recabó cooperación y asistencia de la comunidad internacional. ${ }^{47}$

A nivel jurisprudencial interno, en sentencia C-177/2005, la Corte Constitucional Colombiana aplicó el análisis de proporcionalidad a medidas estatales acusadas de limitar derechos laborales sobre la base de la inconstitucionalidad prima facie de las medidas regresivas y señaló:

Finalmente, y de particular importancia en el presente caso, el mandato de progresividad implica que una vez alcanzado un determinado nivel de protección, la amplia libertad de configuración del legislador en materia de derechos sociales se ve restringida, al menos en un aspecto: todo retroceso frente al nivel de protección alcanzado es constitucionalmente problemático puesto que precisamente contradice el mandato de progresividad. Ahora bien, como los Estados pueden enfrentar dificultades, que pueden hacer imposible el mantenimiento de un grado de protección que había sido alcanzado, es obvio que la prohibición de los retrocesos no puede ser absoluta sino que debe ser entendida como una prohibición prima facie. Esto significa que, como esta Corte ya lo había señalado, un retroceso debe presumirse en principio inconstitucional, pero puede ser justificable, y por ello está sometido a un control judicial más severo. Para que pueda ser constitucional, las autoridades tienen que demostrar que existen imperiosas razones que hacen necesario ese paso regresivo en el desarrollo de un derecho social. ${ }^{48}$

En todo caso, es importante admitir que la tutela y garantía efectiva de los derechos fundamentales está directamente relacionada con la situación económica de cada Estado. Y es común observar que, en casos de crisis económica, los primeros derechos en ser recortados son los derechos sociales ya garantizados..$^{49}$ Es comprensible que debido a limitaciones presu-

47 Ibidem, punto 10.

48 Corte Constitucional de Colombia, sentencia C-177/05, 1o. de marzo de 2005, fj. 22 .

49 Tal es el caso de países como España, Portugal y Grecia, que han dado importantes pasos regresivos respecto al diseño de políticas sociales y económicas para el desarrollo de los derechos humanos, en general, y los sociales, en particular. El caso de estos tres países europeos es dramático y hasta la fecha, su futuro económico es incierto. Los datos obtenidos hasta el día de hoy son desesperanzadores. La crisis económica ha originado impactantes revueltas sociales y aun así, por ejemplo, el 6 de junio del 2013, España anunciaba los recortes de hasta el $6 \%$ anual de las pensiones de los jubilados. El caso de los derechos sociales en Grecia es actualmente, un camino sin salida. Los objetivos de reducción del déficit y la deuda impuestos por la Troika han significado el recorte de los 
Esta revista forma parte del acervo de la Biblioteca Jurídica Virtual del Instituto de Investigaciones Jurídicas de la UNAM

puestarias en una sociedad democrática, se pueda priorizar la realización de unos derechos sobre otros; sin embargo, esta decisión debe ser justificada y señalada claramente y no afirmarse que unos derechos pueden exigirse a los poderes públicos porque requieren sólo de una abstención, mientras otros derechos deben quedar al arbitrio del legislador, ya que implican acciones estatales positivas. Finalmente, lo importante es reflexionar hasta qué punto este argumento está fundamentado en posiciones científica-jurídicas y no exclusivamente en posiciones político-ideológicas.

\section{El legislador goza de libre discrecionalidad en el desarrollo de los derechos sociales}

Este argumento sostiene que la intervención judicial en los derechos sociales afectaría las competencias del legislador en la materia como poder legitimado a través de las urnas y significaría la adjudicación por parte del juez de funciones que no le corresponden. Esta posición ha sido defendida por Forsthoff y, posteriormente, también por Böckenforde. Estos autores coinciden en que los derechos sociales, por ser derechos inconcretos, requieren de su desarrollo por parte del legislador. Para Forsthoff, ésta es la razón por la cual "los derechos sociales no se pueden captar en una norma abstracta susceptible de interpretación". ${ }^{50}$ A su vez, Böckenforde afirma que "si se encomendara al juez la aplicación inmediata de derechos fundamentales sociales mediante la concesión de pretensiones jurídicas concretas y reclamables, debería desempeñar al mismo tiempo el papel del legislador y del administrador". ${ }^{51}$

Señala Courtis que asumir los derechos sociales como "derechos de configuración legal", ${ }^{52}$ en el paradigma positivista, implica dos cuestiones: 1)

gastos públicos, que incluyeron servicios fundamentales como el empleo y la atención sanitaria, sin ninguna consideración por la necesidad de preservar los niveles mínimos y cumplir con las obligaciones básicas respecto a estos derechos. Al día de hoy, en estos países, la situación no ha logrado revertirse.

50 Forsthoff, E., "Concepto y esencia del Estado social de derecho", en Forsthoff, Abendroth y Doering, El Estado social, Madrid, Centro de Estudios Constitucionales, 1986, p. 86.

51 Bockenforde, E., Escritos sobre derechos ..., cit., p. 78.

52 Pisarello define "derechos de configuración legal" como "...derechos que necesitan de la interposición y desarrollo de la ley para hacerse valer en un juicio". Pisarello, G., "Derechos sociales, democracia e inmigración en el constitucionalismo español: del 
Esta revista forma parte del acervo de la Biblioteca Jurídica Virtual del Instituto de Investigaciones Jurídicas de la UNAM

que con independencia del reconocimiento constitucional, su exigibilidad depende de su desarrollo por parte del legislador, ${ }^{53}$ y 2) que el legislador, con base en su legitimidad democrática, goza de amplia discrecionalidad para proceder o no con el desarrollo legislativo del derecho social. ${ }^{54}$ En este paradigma, como los derechos sociales son "programas", deben ser desarrollados legislativamente, para lo cual el legislador requiere de amplia discrecionalidad en los asuntos que le competen, como el caso de diseños de políticas públicas en materia de derechos sociales. Sin embargo, si analizamos la función legislativa en materia de derechos sociales desde la óptica neoconstitucionalista, el escenario cambia.

En el paradigma neoconstitucional, no se niega que los derechos sociales requieran de desarrollo legislativo para ser efectivos. Sin embargo, esto no quiere decir que su solo reconocimiento constitucional no imponga límites infranqueables al legislador ni que no gocen de cierta dimensión de exigibilidad judicial. Señala Bastida que la Constitución, como fuente jurídica directamente aplicable, los dota de una disponibilidad por su titular potencialmente inmediata pues “...preserva a los derechos fundamentales de su alteración o vulneración por normas constitucionales e infraconstitucionales y los hace indisponibles para el legislador". ${ }^{55}$

Además, desde una perspectiva amplia, todos los derechos fundamentales son derechos de configuración legal pues exigen, en mayor o menor medida, del desarrollo legislativo de sus contenidos. Al respecto, Pisarello afirma que "...su plena eficacia (la de los derechos fundamentales) resultaría impensable sin una activa intervención legislativa". ${ }^{56}$ Sostiene el autor que la ley es una fuente privilegiada de producción jurídica en los ordenamientos modernos y constituye una garantía primaria para la satisfacción de cualquier derecho. En este sentido, "todos los derechos fundamentales

originalismo a una interpretación sistemática y evolutiva", en Añón, M. J., La universalidad de los derechos: el reto de la inmigración, Valencia, Universidad de Valencia, 2004, p. 68.

53 Cossio Díaz, J. R., Dogmática constitucional y régimen autoritario, México, Fontamara, 2000.

54 Courtis, C., El mundo prometido..., cit.

55 Bastida, J., “'Son los derechos sociales derechos fundamentales? Por una concepción normativa de la fundamentalidad de los derechos", en Alexy, Robert, Derechos sociales y ponderación, México, Fontamara, 2010, pp. 103-150.

56 Pisarello, G., Los derechos sociales y sus garantías..., cit., p. 83. 
Esta revista forma parte del acervo de la Biblioteca Jurídica Virtual del Instituto de Investigaciones Jurídicas de la UNAM

exigen concreciones legislativas que pueden tener diferentes alcances". ${ }^{57}$ Sin embargo, el desarrollo legislativo del derecho sí determinará su grado de exigibilidad judicial. La mayor o menor regulación legal reforzará o debilitará las posibilidades de exigibilidad judicial del derecho individual o social. Pero, para Pisarello "esto no impide reconocer que todos ellos tienen un contenido constitucional mínimo, indisponible y susceptible de algún tipo de tutela jurisdiccional incluso en el caso de inexistencia de desarrollo legal". ${ }^{8}$ La idea de fondo, tal como la expresa Espejo, es que sin el respeto de ese contenido mínimo esencial, ya sea limitándolo o sobreinterpretándolo, el derecho quedaría desnaturalizado y la dignidad de sus destinatarios menoscabada. ${ }^{59}$

Ahora bien, la cuestión que quedaría por resolver es la forma como se determina el contenido mínimo esencial de un derecho social. Defendemos la idea de que este contenido mínimo esencial sólo puede determinarse en el momento de la aplicación concreta del derecho. Los elementos del derecho social no se pueden observar en abstracto, sino que requieren ser contextualizados, adoptando los elementos de cada caso concreto. Además, exige una constante revisión histórica. Es aquí donde juega un papel fundamental la interrelación entre la función de juzgar y la de legislar. Al respecto, sostiene Pisarello que si bien la frontera entre el núcleo duro y lo accidental del derecho social no será siempre clara y deberá concretizarse a partir de su contextualización, una vez determinado el contenido esencial del derecho, éste

será también una barrera insoslayable y en ningún caso inexistente que obliga a un permanente trazado de límites entre justicia y política, entre jueces y legisladores. Esta tarea de delimitación supone una división de tareas conflictiva y nunca resuelta de antemano, en la que los primeros deben preservar el contenido mínimo de los diferentes derechos y los segundos mantenerlos y desarrollarlos, pero nunca aniquilarlos o desvirtuarlos, por acción u omisión. ${ }^{60}$

Ibidem, p. 84.

Idem.

59 Espejo, N., "Derechos sociales, republicanismo y Estado de derecho: un modelo de justiciabilidad", en Arcidiácono, Pilar et al. (coords.), Derechos sociales: justicia, política y economía en América Latina, Bogotá, Siglo del Hombre, 2010, pp. 155-194.

${ }^{60}$ Ibidem, pp. 85 y 86. 
Esta revista forma parte del acervo de la Biblioteca Jurídica Virtual del Instituto de Investigaciones Jurídicas de la UNAM

La incidencia tanto del legislador como del juez en el desarrollo de mecanismos de protección de los derechos sociales es, actualmente, uno de los puntos más debatidos por la doctrina constitucional. ${ }^{61}$ La cuestión radica en la supuesta usurpación de funciones legislativas por parte del juez al momento de interpretar el contenido del derecho social. Este argumento señala que los tribunales jurisdiccionales no deberían intervenir en la protección de derechos sociales a menos que existan normas desarrolladas por parte del legislador.

Coincidimos en esta discusión con Rodolfo Arango, quien señala que los derechos sociales fundamentales "hacen parte de los constitutional essentials que el juez está llamado a reconocer y proteger frente al poder de las mayorías". ${ }^{62}$ Esto es congruente con el nuevo rol del juez en el constitucionalismo contemporáneo. En este contexto, señala Ibáñez que "resulta aberrante que pueda ponerse en duda la legitimidad del juez para actuar, y más aún que esto se haga en nombre de la democracia". ${ }^{63}$ Por otro lado, el juez debe delimitar sus acciones al análisis de las cuestiones jurídicoconstitucionales y no pretender decidir en asuntos que exceden de sus competencias. Cuando existe un exceso de activismo judicial, en el que el juez no vislumbra la delgada línea entre decidir sobre el contenido del derecho social y decidir sobre las formas de intervención o dictar medidas que afectan las funciones constitucionales del Legislativo o del Ejecutivo, se desvirtúa la función judicial y se justifica la crítica en torno a la falta de legitimidad de la actuación del juez y su intromisión en asuntos para los cuales no es competente. En este caso existe un temor a que se "judicialicen" en exceso las políticas sociales, temiendo en realidad lo que Troper define como un "gobierno de jueces", en la determinación del presupuesto del Estado o en el diseño de políticas públicas. ${ }^{64}$

61 Véase Michelman, T., "The Constitution, Social rights and Liberal justification", International Journal of Constitutional Law, Oxford, Oxford University Press and New York University School of Law, vol. 1, núm. 1, 2011, pp. 13-34.

62 Arango, R., "La justiciabilidad de los derechos sociales fundamentales", Revista de Derecho Público, Bogotá, Universidad de los Andes, Facultad de Derecho, núm. 12, junio de 2001, pp. 198.

63 Ibáñez, P., "Democracia con jueces", en Malem, Jorge et al. (comps.), La función judicial. Ética y democracia, Barcelona, Gedisa, 2003, p. 250.

64 Troper, Michel, "Existe-t-il un concept de gouvernement des juges?", en Brondel, S. et al., Gouvernement des juges et Democratie, París, Publications de la Sorbonne, 2001, pp. 21-62. 
Esta revista forma parte del acervo de la Biblioteca Jurídica Virtual del Instituto de Investigaciones Jurídicas de la UNAM

Reconocer los peligros que un exceso de judicialización puede ocasionar no cambia en esencia el rol que juega el juez en la protección de los derechos sociales en el paradigma neoconstitucional. Mientras el juez esté determinado en su actuación por la Constitución y sus normas, su función jurisdiccional es fundamental para la garantía de los derechos sociales. Sobre todo en los casos en que las garantías políticas-institucionales han fallado o en los casos en los que, de plano, no se ha legislado al respecto. Además, el desarrollo jurisprudencial de los derechos sociales, en cuanto a su contenido y a las fórmulas posibles para hacerlo efectivo, puede dar luces y orientar al legislador respecto a las dimensiones del problema social, la necesidad y los alcances de protección del derecho. Como afirma De Lima López, el Poder Judicial, provocado adecuadamente, puede ser "un poderoso instrumento de formación de políticas públicas". ${ }^{65}$

Y no sólo de formación, además la intervención judicial también resulta útil para el análisis sobre la efectividad real de las políticas públicas en materia de derechos sociales y la puesta en marcha de soluciones, en un ejercicio jurisdiccional a lo que se ha llamado "constitucionalismo dialógico" que se ha venido desarrollando en este ámbito desde mediados de los años ochenta. Éste consiste, en palabras de Gargarella, “...en una práctica según la cual los asuntos constitucionales fundamentales deber ser resueltos mediante una conversación extendida, persistente en el tiempo, y que debe involucrar a las distintas ramas del poder, tanto como la propia ciudadanía". ${ }^{66}$

A pesar que en algunos países del common law este "diálogo" se ha venido desarrollando desde hace algunos años, en América Latina lo inauguró la Corte Constitucional de Colombia. En efecto, se desarrolló "jurisprudencia dialógica” en la macrosentencia T-025 del 2004, donde se evidenció que las fallas estructurales de las políticas públicas del Estado colombiano habían contribuido a la violación masiva y reiterada de los derechos humanos (entre ellos los derechos sociales) de la población desplazada por la violencia. ${ }^{67}$

65 Lima, R. de, "Direito subjetivo e direitos sociais: o dilema do judiciário no Estado Social de direito", en Faria, J. (ed.), Direitos humanos, direitos sociais e justica, Sao Paulo, Malheiros, 1994, pp. 114-138.

66 Gargarella, R. (comp.), Por una justicia dialógica: el Poder Judicial como promotor de la deliberación democrática, Buenos Aires, Siglo XXI Editores, 2014, p. 10.

67 Véase Rodríguez Garavito, César y Rodríguez, Diana, "Un giro en los estudios sobre derechos sociales: El impacto de los fallos judiciales y el caso del desplazamiento forzado en Colombia", en Arcidiácono, Pilar et al. (coords.), Derechos sociales: justicia, política y economía en América Latina, cit. 
Esta revista forma parte del acervo de la Biblioteca Jurídica Virtual del Instituto de Investigaciones Jurídicas de la UNAM

Posteriormente, lo desarrolló la Suprema Corte de Justicia de Argentina en el 2008 para la sentencia del caso Matanza-Riachuelo sobre contaminación ambiental en la provincia de Buenos Aires. A efectos de llegar a una decisión, la Corte convocó a una serie de audiencias públicas en donde se reunieron los distintos afectados, así como los poderes públicos involucrados y organizaciones civiles con la finalidad de encontrar colectivamente soluciones a los "problemas estructurales" que se debatían en sede jurisdiccional, a través del diálogo interpartes. ${ }^{68}$

En el plano internacional, los distintos órganos internacionales competentes han reiterado que las obligaciones contenidas en los tratados internacionales en materia de derechos sociales vinculan a todos los poderes del Estado de igual manera, por lo cual se requiere de una coordinación entre éstos a fin de garantizar el cumplimiento de las mismas. En efecto, el Comité de los Derechos Económicos, Sociales y Culturales de las Naciones Unidas ha desarrollado, a partir de su análisis de las obligaciones del Pacto de Derechos Económicos, Sociales y Culturales de 1966, las obligaciones estatales mínimas en la materia. En oportunidad a la Observación General núm. 3 de 1990, señaló que la obligación de adoptar medidas, la obligación de garantizar niveles esenciales de derechos y la obligación de progresividad y su correlativa prohibición de regresividad resultan vinculantes y de cumplimiento inmediato para los Estados parte. ${ }^{69}$ Evidentemente, estas obligaciones constituyen un mínimo que el legislador debe respetar y garantizar. Su discrecionalidad en referencia al desarrollo de los derechos sociales queda condicionada al cumplimiento de estas obligaciones internacionales y al contenido mínimo del derecho social. Lo señalado por el Comité resulta vinculante respecto a los Estados parte del Pacto, que son casi la totalidad de Estados iberoamericanos.

68 Suprema Corte de Justicia de la Nación Argentina, Sentencia del caso Mendoza, Beatriz Silvia y otros c/ Estado Nacional y otros s/ daños y perjuicios (daños derivados de la contaminación ambiental del Río Matanza - Riachuelo), M. 1569. XL, 8 de julio de 2008 .

69 Comité de Derechos Económicos, Sociales y Culturales de la OrGanizaCIÓN DE NACIONES UNIDAS, Observación General núm. 3: La índole de las obligaciones de los Estados Partes, 1990. 
Esta revista forma parte del acervo de la Biblioteca Jurídica Virtual del Instituto de Investigaciones Jurídicas de la UNAM

\section{La inexistencia de garantías jurisdiccionales para la efectividad de los derechos sociales}

Finalmente, todos los argumentos derivan en esta tesis central de la posición que defiende la no justiciabilidad de los derechos sociales: no son justiciables pues no existen garantías jurisdiccionales diseñadas para tal efecto. El escaso desarrollo de un sistema de garantías jurisdiccionales de los derechos sociales tiene su razón en la perspectiva programática del primer constitucionalismo social y en la enunciación de estos derechos en los tratados internacionales sobre la materia, donde se evidencia la tendencia positivista-liberal del sistema de derechos humanos en los que surgieron los derechos sociales durante el constitucionalismo de la posguerra. En este contexto, las acciones judiciales tipificadas por los ordenamientos jurídicos fueron pensadas para la protección de los derechos civiles y políticos clásicos. ${ }^{70}$

Desde la óptica neoconstitucional, éste no es un argumento sólido para defender la idea de que los derechos sociales no pueden ser justiciables. Desde este paradigma, las posturas están divididas en referencia al grado de protección, mas no en referencia a la posibilidad de su exigibilidad judicial. Al respecto, Pisarello suscribe un argumento validado por la mayoría de doctrina autorizada en el tema: que al considerar los derechos sociales como derechos fundamentales, su sola consagración constitucional "obliga a los operadores jurídicos a maximizar, bien por vía interpretativa, bien por medio de reformas, los mecanismos que permitan su protección". ${ }^{71}$ En este sentido, la ausencia de garantías jurisdiccionales entraña el incumplimiento o cumplimiento defectuoso por parte de los operadores jurídicos, del mandato implícito de actuación contenido en dicha norma. Entendido así, afirma el autor que "no es el derecho el que queda degradado, sino el poder el que incurre en una actuación desviada o en una omisión que lo deslegitima". ${ }^{72}$ En la misma línea de pensamiento, Ferrajoli afirma que "la ausencia de garantías debe ser considerada como una indebida laguna que los poderes públicos internos e internacionales tienen la obligación de colmar". ${ }^{73} \mathrm{Y}$ esto porque, en el paradigma neoconstitucional, las garantías "no se confunden

70 Abramovich,V. y Courtis, C., Derechos sociales como derechos exigibles, Madrid, Trotta, 2002.

71 Pisarello, G., Los derechos sociales..., cit., p. 81.

72 Idem.

73 Ferrajoli, L., Derechos y garantías: la ley del más débil, Madrid, Trotta, 1999, p. 63. 
con la estructura de los derechos, sino que se vinculan estrechamente a la efectividad o concreción fáctica del contenido de estos derechos". ${ }^{74}$

Por otro lado, en la realidad latinoamericana es evidente que el argumento positivista de la inexistencia de garantías jurisdiccionales para la efectividad de los derechos sociales ha servido de excusa a la falta de interés y voluntad política, por no decir también de creatividad de los legisladores. Como sostiene Peña: “...más que problemas de técnica jurídica, el problema real es la falta de voluntad política para hacer efectivos los derechos sociales, utilizando razones de supuestas "carencias técnicas' como pretexto". ${ }^{75}$ Aquí se produce un efecto circular: mientras el positivismo jurídico insista en que los derechos sociales no pueden ser exigibles porque no existen mecanismos para ello, el legislador seguirá justificando la falta de desarrollo de estos mecanismos en lo señalado por la doctrina. Esto es insostenible desde el paradigma neoconstitucional por las razones que ya hemos señalado.

En definitiva, la tendencia a analizar los derechos sociales como derechos exigibles - y en efecto, justiciables - surge a partir de la actividad jurisprudencial nacional e internacional, donde incluso ha sido el origen de cambios legislativos para abarcar los derechos sociales en los diversos mecanismos nacionales de protección jurisdiccional de los derechos fundamentales. Por ejemplo, en años recientes, los tribunales latinoamericanos han venido utilizando los mecanismos jurisdiccionales internos para la tutela de los derechos fundamentales (como las acciones de amparo, de tutela o el mandado de injunção) y de la supremacía constitucional (la acción de inconstitucionalidad y la inconstitucionalidad por omisión), además de sus aptitudes hermenéuticas para garantizar derechos sociales, aun ante la inexistencia de legislación que desarrollara los derechos sociales o en el caso que la legislación no abarcara ciertos supuestos o colectivos. Así, a nivel jurisprudencial, existen diversos mecanismos que han sido aplicados por los tribunales para garantizar judicialmente estos derechos. En mayor medida se han reconocido derechos sociales por su vinculación con otros derechos individuales (por ejemplo el derecho a la salud y el derecho a la vida), pero también existen casos en los que se ha garantizado derechos

74 Aldunate, E., Derechos fundamentales, Santiago, Legal Publishing, 2008, p. 110.

75 Peña, A., La garantía en el Estado constitucional de derecho, Madrid, Trotta, 1997 , p. 57. 
Esta revista forma parte del acervo de la Biblioteca Jurídica Virtual del Instituto de Investigaciones Jurídicas de la UNAM

sociales de manera autónoma (como derecho subjetivo o como parámetro de validez de la Constitución). ${ }^{76}$

Por otro lado, también se han adaptado los mecanismos jurisdiccionales procesales diseñados para la defensa de los derechos individuales a las exigencias de la tutela de derechos sociales como el caso argentino y el amparo colectivo $^{77}$ o el caso colombiano y la macrosentencia T- 025 del 2004. En algunos casos, se ha ampliado la protección jurisdiccional de los derechos sociales al proceso de amparo como el caso de Perú, donde el Código Procesal Constitucional del 2004 menciona explícitamente como derechos susceptibles de ser tutelados por esta vía a los derechos sociales reconocidos en la Constitución además de los derechos sociales "innominados" que estén reconocidos en los tratados internacionales sobre la materia o que se funden en la dignidad del hombre y en los principios del Estado social de derecho. Finalmente, algunos países han consagrado la justiciabilidad universal de los derechos fundamentales a nivel constitucional, como es el caso de Venezuela ${ }^{78}$ o Bolivia. ${ }^{79}$

\section{CONCLUSIONES}

Hasta aquí, hemos desarrollado un análisis teórico y jurisprudencial de los clásicos postulados positivistas en torno a la justiciabilidad de los derechos sociales a partir del neoconstitucionalismo. Hemos demostrado que a la luz de los presupuestos del paradigma neoconstitucional, los derechos sociales son verdaderos derechos fundamentales susceptibles de ser exigibles jurisdiccionalmente.

76 Un estudio de casos y análisis de contenido sobre estas sentencias se observa en la tesis doctoral elaborada por la autora de este artículo. En la tesis de próxima publicación es posible observar a detalle los mecanismos diseñados por los tribunales constitucionales peruano y colombiano para la garantía de los derechos sociales. Este análisis se desarrolla a partir de tres elementos que definen cada sentencia: 1) la naturaleza del proceso constitucional del que derivan, 2) el efecto de la sentencia, y 3 ) el elemento generador de justiciabilidad. Espino, D., Derechos sociales y justiciabilidad: el Tribunal Constitucional peruano y su jurisprudencia en materia de derechos sociales fundamentales (20022008), México, UANL, tesis inédita, 2015.

77 Artículo 43 de la Constitución de la Nación Argentina, reformada en 1994.

78 Artículo 27 de la Constitución de la República Bolivariana de Venezuela de 1999.

79 Artículo 109 de la Constitución del Estado Plurinacional de Bolivia de 2009. 
Consecuentemente, concluimos que en este paradigma, los derechos sociales: 1) constituyen derechos subjetivos desde una visión evolucionada del concepto, en el marco del Estado social de derecho, 2) son derechos positivos, si se entienden como derechos de diferentes niveles obligacionales determinables en cada caso concreto, 3) son derechos que exigen costos, como todos los derechos fundamentales, lo que no obsta para que se adecue la economía estatal al cumplimiento de las exigencias mínimas de estos derechos, 4) limitan la "discrecionalidad del legislador", la cual está condicionada a demostrar que ha actuado en conformidad con las exigencias constitucionales de los derechos sociales, como el respeto del contenido mínimo esencial y la obligación de progresividad de los derechos sociales, 5) son susceptibles de ser exigibles judicialmente, pues la justicia constitucional comparada ha demostrado que se puede garantizar jurisdiccionalmente estos derechos aun en ausencia de garantías específicas. En este sentido, consideramos que la falta de garantías jurisdiccionales no tiene origen en la estructura de los derechos, sino en cuestiones meramente políticas.

Considerar a los derechos sociales como verdaderos derechos fundamentales ha disparado una cada vez más prolija literatura sobre el tema, así como un mayor activismo por parte de las cortes. Esta "revolución" no ha sido para nada pacífica y con cada avance surgen nuevas críticas, las cuales retoman los "clásicos" argumentos aquí comentados. Calificar hoy los argumentos del positivismo como válidos significa cerrar los ojos ante la evolución del derecho como ciencia, además de persistir en presupuestos del positivismo que ya se han visto ampliamente superados. Por último, al defender los derechos sociales como derechos exigibles de manera judicial, no se está nadando contracorriente todo lo contrario, se está justificando su exigibilidad a partir de la corriente científica que en la actualidad inspira al derecho.

\section{BIBLIOGRAFÍA}

Abramovich, V. y Courtis, C., Derechos sociales como derechos exigibles, Madrid, Trotta, 2002.

Aguiló, J., "Positivismo y post-positivismo. Dos paradigmas jurídicos en pocas palabras", Doxa. Cuadernos de Filosofía del Derecho, Alicante, Universidad de Alicante, núm. 30, 2007.

AlduAte, E., Derechos fundamentales, Santiago, Legal Publishing, 2008. 
Esta revista forma parte del acervo de la Biblioteca Jurídica Virtual del Instituto de Investigaciones Jurídicas de la UNAM

Alexy, R., Teoría de los derechos fundamentales, Madrid, Centro de Estudios Constitucionales, 1997.

Aragón, M., "La Constitución como paradigma", en CARBOnell, Miguel (comp.), Teoría de la Constitución, México, Porrúa, 2008.

ARANGO, R., "La justiciabilidad de los derechos sociales fundamentales", Revista de Derecho Público, Bogotá, Universidad de los Andes, Facultad de Derecho, núm. 12, junio de 2001. 2005.

AtRIA, F., “¿Existen derechos sociales?”, Discusiones, La Pampa, Universidad Nacional del Sur, año 4, núm. 4, febrero de 2005.

BASTIDA, J., “¿Son los derechos sociales derechos fundamentales? Por una concepción normativa de la fundamentalidad de los derechos", en ALEXY, Robert, Derechos sociales y ponderación, México, Fontamara, 2010.

BOCKENFORDE, E., Escritos sobre derechos fundamentales, Baden-Baden, Nomos, 1993.

Bustos, R., "Derechos sociales: desmontando prejuicios", en FigUEROA, Aida, Los derechos humanos en los umbrales del siglo XXI, México, UNAM, Instituto de Investigaciones Jurídicas, 2012.

CONTRERAS, J., Derechos sociales: teoría e ideología, Madrid, Tecnos, 1994.

Cossío DíAz, J. R., Dogmática constitucional y régimen autoritario, México, Fontamara, 2000.

CourTis, C., El mundo prometido. Escritos sobre derechos sociales y derechos humanos, México, Fontamara, 2009.

CRUZ PARCERO, J., "Derechos sociales: clasificaciones sospechosas y delimitación conceptual", en CANTÓN, Octavio y CORCUERA, Santiago (coords.), Derechos económicos, sociales y culturales. Ensayos y materiales, México, Porrúa, 2004.

, El lenguaje de los derechos. Ensayo para una teoría estructural de los derechos, Madrid, Trotta, 2007.

ESPEJO, N., "Derechos sociales, republicanismo y Estado de derecho: un modelo de justiciabilidad", en ARCIDIÁCONO, Pilar et al. (coords.), Derechos sociales: justicia, politica y economía en América Latina, Bogotá, Siglo del Hombre, 2010.

EsPINO, D., Derechos sociales y justiciabilidad: El Tribunal Constitucional Peruano y su jurisprudencia en materia de derechos sociales fundamentales (2002-2008), Monterrey, UANL, tesis inédita, 2015. 
Esta revista forma parte del acervo de la Biblioteca Jurídica Virtual del Instituto de Investigaciones Jurídicas de la UNAM

FERRAJOLI, L., "Estado social y Estado de derecho", en ABrAMOVICH, Víctor et al. (comps.), Derechos sociales: instrucciones de uso, México, Fontamara, 2003.

, Derechos y garantías: la ley del más débil, Madrid, Trotta, 1999.

ForsthofF, E., "Concepto y esencia del Estado social de derecho", en ABEndroth et al., El Estado social, Madrid, Centro de Estudios Constitucionales, 1986.

GARCíA, E., "Sobre los derechos públicos subjetivos", Revista Española de Derecho Administrativo, Madrid, Civitas, 1975.

GARCíA, L., "Buenos tiempos para el neoconstitucionalismo", Universitas, Bogotá, núm. 120, enero-junio de 2010.

Gargarella, R. et al. Por una justicia dialógica: El Poder Judicial como promotor de la deliberación democrática, Buenos Aires, Siglo XXI Editores, 2014.

GonZÁlez, B., El Estado social, Madrid, Civitas, 2002.

Guastini, R., "Derechos", Distinguiendo, Barcelona, Gedisa, 1999.

HAYEK, F., Derecho, legislación y libertad. El espejismo de la justicia social, Madrid, Unión Editorial, 1979, vol. 2.

Holmes, S. y Sustein, C., The Cost of Rights: Why Liberty Depends on Taxes, Nueva York, W.W. Norton, 1999.

IBÁÑEZ, P., "Democracia con jueces", en MALEM, Jorge et al. (comps.), La función judicial. Ética y democracia, Barcelona, Gedisa, 2003.

LANDA, C., Derechos fundamentales y justicia constitucional, México, Porrúa, 2011.

LIMA, R. de, "Direito subjetivo e direitos sociais: o dilema do judiciário no Estado Social de direito", en FARIA, J. (ed.), Direitos humanos, direitos sociais e justica, Sao Paulo, Malheiros, 1994.

Melo de Moraes, N., La contribución del Poder Judicial a la protección de los derechos humanos de tercera generación: especial referencia al derecho al desarrollo, Salamanca, Universidad de Salamanca, 2014.

Michelman, "The Constitution, Social Rights and Liberal Justification", International Journal of Constitutional Law, Oxford, Oxford University Press-New York University School of Law, vol. 1, núm. 1, 2003.

PEÑA, A. La garantía en el Estado constitucional de derecho, Madrid, Trotta, 1997.

Pietro SANChís, L., "Neoconstitucionalismo y ponderación judicial", Anuario de la Facultad de Derecho, Madrid, Universidad Autónoma de Madrid, 2001. 
Esta revista forma parte del acervo de la Biblioteca Jurídica Virtual del Instituto de Investigaciones Jurídicas de la UNAM

Ley, principios, derechos, Madrid, Dykinson, 1998.

PISAREllo, G., Los derechos sociales y sus garantías, Madrid, Trotta, 2007.

, "Derechos sociales, democracia e inmigración en el constitucionalismo español: del originalismo a una interpretación sistemática y evolutiva", en AÑón, M. J., La universalidad de los derechos: el reto de la inmigración, Valencia, Universidad de Valencia, 2004.

RODRÍGUEZ, C. y RODRÍGUEZ, D., "Un giro en los estudios sobre derechos sociales: el impacto de los fallos judiciales y el caso del desplazamiento forzado en Colombia", en ARCIDIÁCONO, Pilar et al. (coords.), Derechos sociales: justicia, política y economía en América Latina, Bogotá, Siglo del Hombre, 2010.

SAlAZAR, P., "Garantismo y neoconstitucionalismo frente a frente: algunas claves para su distinción", Doxa. Cuadernos de Filosofía del Derecho, núm. 34, 2001.

SEPÚlVEDA, M., "La justiciabilidad de los derechos económicos, sociales y culturales frente a la supuesta dicotomía entre las obligaciones impuestas por los pactos de Naciones Unidas", en CANTÓN, Octavio y Corcuera, Santiago (coords.), Derechos económicos, sociales y culturales. Ensayos y materiales, México, Porrúa, 2004.

TORRES DEL Moral, A., "Naturaleza de los derechos constitucionales", Revista de Derecho de la Universidad Católica de Valparaíso, Valparaíso, Universidad Católica, vol. XVIII, 1997.

TROPER, Michel, "Existe-t-il un concept de gouvernement des juges?", en Brondel, S. et al., Gouvernement des juges et Democratie, París, Publications de la Sorbonne, 2001.

Fecha de recepción: 29 de septiembre de 2015.

Fecha de dictamen: 12 de diciembre de 2015. 